\title{
Central nervous system autopsy - a neuropathological procedure based on multidisciplinary pathoclinical cooperation
}

\author{
Aleksandra Sejda ${ }^{1}$, Teresa Wierzba-Bobrowicz², Dariusz Adamek³ Jacek Gulczyński ${ }^{4}$, \\ Sławomir Michalak ${ }^{5}$, Wiesława Grajkowska ${ }^{6}$, Ewa Iżycka-Świeszewska ${ }^{7}$ \\ ${ }^{1}$ Pathomorphology Department, Collegium Medicum, University of Warmia and Mazury, Olsztyn, Poland \\ ${ }^{2}$ Department of Neuropathology, Institute of Psychiatry and Neurology, Warsaw, Poland \\ ${ }^{3}$ Department of Pathology, Jagiellonian University Medical College, Krakow, Poland \\ ${ }^{4}$ Department of Pathology and Neuropathology, Medical University of Gdansk, Poland
}

${ }^{5}$ Department of Neurology, Division of Neurochemistry and Neuropathology, Poznan University of Medical Science, Poznan, Poland

${ }^{6}$ Department of Pathology, Children's Memorial Health Institute, Warsaw, Poland

${ }^{7}$ Department of Pathology and Neuropathology, Medical University of Gdansk, Poland

\begin{abstract}
Introduction: Neuropathological brain and spinal cord post mortem examination is a distinct procedure that still plays an important role in modern medicine. In front of increasing amounts of clinical and genetic data, together with important developments in the field of neuroimaging, the Polish Association of Neuropathologists have updated their recommendations regarding central nervous system (CNS) examination. These guidelines are aimed at neuropathologists, pathologists and clinicians.

Aim of the study: Presentation of the outlined recommendations as their goal is to improve the quality, informativity, and cost effectiveness of CNS post mortem examinations. A comprehensive study of the literature was conducted to provide a clinical background of neuropathological autopsy. There are numerous open questions in neuroscience, and new strategies are required to foster research in CNS diseases. These include the challenge of organizing brain banks tasked with managing and protecting detailed multidisciplinary information about their resources. Complex neuropathological analyses of post mortem series are also important to assess the effectiveness of diagnostics and therapy, identify environmental impact on the development of neurological disorders, and improve public health policy. The recommendations outline the need for collaboration between multiple specialists to establish the proper diagnosis and to broaden knowledge of neurological disorders.
\end{abstract}

Key words: brain and spinal cord dissection, guidelines, neuropathology, pathoclinical cooperation

(Neurol Neurochir Pol 2022; 56 (2): 118-130)

\section{Introduction}

Central nervous system (CNS) post mortem neuropathological examination is a comprehensive medical examination performed in order to identify the cause of death, verify the clinical diagnosis, confirm the morphological background of the clinically discovered primary disease, identify any secondary or concomitant changes in the brain and/or spinal cord, and reconstruct the course of disease events [1-3]. The neuropathological post mortem is important for doctors and other medical staff, as well as for administration as it helps with monitoring the quality of health services by verifying

Address for correspondence: Ewa Iżycka-Świeszewska, Department of Pathology and Neuropathology, Medical University of Gdansk, Dębinki 1 Str.,

80-211 Gdańsk, Poland; e-mail: ewa.izycka-swieszewska@gumed.edu.pl

Received: 9.08.2020 Accepted: 21.10.2021 Early publication date: 16.12 .2021

This article is available in open access under Creative Common Attribution-Non-Commercial-No Derivatives 4.0 International (CC BY-NC-ND 4.0) license, allowing to download articles and share them with others as long as they credit the authors and the publisher, but without permission to change them in any way or use them commercially. 
the adopted diagnostic and therapeutic procedures. In addition, it allows the detection of infectious, toxic, genetically determined, environmental and occupational diseases, and often indicates an aetiological factor [4]. An additional aim of the CNS dissection is the maintenance of the principles of good clinical practice and the long-term development of neuroscience $[2,5,6]$.

Despite enormous progress in medicine, in many cases it is still not possible to make an unambiguous diagnosis during hospitalisation and to determine the causes of a patient's death, and complete correctly death report. Additionally, as shown by correlation analyses of clinical and sectional diagnoses, in about $15-30 \%$ of cases there are incompatibilities even in hospitalised patients examined in detail $[3,7]$. Neuroimaging has become a basic diagnostic tool used in modern neurology; however, its accuracy is still insufficient [8]. Therefore, the neuropathological autopsy remains in many cases the final means of establishing a clinical diagnosis in many situations [9]. Despite this, a significant decrease in the number of referrals for post mortem examinations of the CNS has been observed in recent years. This is mainly due to financial constraints, changes in clinical attitudes to autopsy in general, and limited access to professional neuropathological diagnostics. In recent decades, there has been a decline in interest in the specialisation of neuropathology, resulting in a decreasing number of qualified personnel [10]. Recently, post mortem brain magnetic resonance imaging (MRI) has become a powerful bridge between clinical phenotypes and histopathological findings [11]. However, this procedure requires special protocols, is available only in selected centres, and has specific indications. The next modern method is virtopsy - a multidisciplinary post mortem virtual examination, mostly used in forensic medicine to perform minimally invasive, observer-independent, objective case investigation, with good documentation quality [12].

A neuropathological post mortem is either an element of a general autopsy examination, including external and internal examination of body organs with taking samples for histopathological examination, or constitutes a separate examination performed in a pathomorphology facility or in a neuropathology lab. It depends mostly on the degree of reference of the medical centre, and the availability of specially trained staff and sophisticated equipment. General pathologists are trained to deal with typical and the more frequently occurring clinical cases. Every unusual situation should be consulted by a qualified neuropathologist in a particular medical centre. Performing a CNS autopsy correctly requires substantial preparation with a thorough knowledge of neuroanatomy, the location of functionally significant structures, the specific topography of pathological processes, and the need to correlate with the overall neurological picture $[2,13]$.

During the post mortem neuropathological examination, recommended standard and selected samples from macroscopically changed regions are taken from the different structures, depending on the clinical and pathological picture. These are then taken to a laboratory for tissue processing and ultimately subjected to microscopic assessment. This may require special additional histochemistry, immunohistochemistry or genetic testing [14-16]. There may also be a need for biochemical, microbiological and/or toxicological examination of specimens and/or cerebrospinal fluid $[9,17]$.

A neuropathological post mortem examination should be conducted based on the relevant guidelines with due diligence, and its results compiled within a specified period to correlate with in vivo clinical and neuroimaging data $[1,9,18]$.

\section{Clinical background}

Historically, most brain diseases, among others Parkinson's Disease, multisystem atrophy, Alzheimer's Disease and amyotrophic lateral sclerosis, were defined and understood based on their clinical course against the background of macroscopic and microscopic CNS examination [19-21]. Rapidly expanding knowledge in neuroscience has brought about changing conceptions regarding multiple neurological diseases. However, in order to verify them, morphological and genetic analyses are still necessary. There is a real need for neuroimaging-neuropathological correlations before, and in parallel with, developing radiological methods, specific contrast media, metabolic and functional imaging. For example, pathological investigation of regions with signal MRI abnormalities and healthy controls has helped to improve MRI imaging and its interpretation in multiple sclerosis diagnosis and treatment [22]. The next illustrative conclusion of such correlations is that post mortem brain analysis of the regions reflecting MRI changes in amyotrophic lateral sclerosis showed a relationship between signal changes and the underlying pathophysiology [23]. Moreover, several conditions might be under-recognised when clinical tests and neuroimaging results are the only factors taken into consideration in establishing a final diagnosis. Thus, the proper treatment, prognosis, and even some global health system statistics and decisions, might be being assessed and incorrectly evaluated [24, 25].

In numerous clinical entities, especially in neurodegenerative diseases, careful assessment of post mortem data has expanded the concepts of their pathobiology, and may even have been crucial in research concerning therapeutic target finding and implementation of clinical trials $[25,26]$. Modern classifications of several groups of neurological diseases, such as leukodystrophies, are founded on complex correlations of clinical course, sequential neuroimaging, pathological findings (including identifying deposits of abnormal proteins) and molecular characteristics [27]. In addition, only careful neuropathological investigations are able to reveal different co-pathologies in examined brains, especially in age-related diseases and dementia [28]. The severity of cognitive impairment in Alzheimer's Disease (AD) has been found to be associated with the distribution, quality and quantification of several pathological findings [25]. Similarly in Parkinson's 
Disease, clinical heterogeneity corresponds to different spatio-temporal and quantitative pathological phenotypes [26]. In recent years, new drugs and therapies have been developed which have substantially extended patient lifespans in numerous entities. In such cases, morphological changes in CNS are not well known. Finally, simulated brain stereotactic biopsy from autopsied brains could help to establish diagnostic algorithms which might be used for proper intravital diagnosis, but also for monitoring changes, including those caused by disease-modifying therapies $[6,29]$.

Brain tissue analysis is becoming more important and more interesting in general medicine, psychiatry, oncology and in infectious diseases (Zika virus, COVID-19), deciphering pathophysiology and consequences of many disorders. Moreover, for a deeper understanding of different diseases, as new research techniques have become more widespread, brain tissue samples should be available for neuroscience research [5, 30-33]. To summarise, much remains to be learned about the clinical phenotypes and corresponding pathological changes in neural tissue, and some risk or protective factors in heterogenic conditions need to be recognised.

What is today crucial for a more effective research of neurological diseases in front of the decreased autopsy rate is the formation of systemic brain banks, together with the collection of comprehensive clinical data. In human brain banks, post mortem and biopsied brain samples are collected, preserved and distributed for histological, pathological, and molecular research $[34,35]$. Such collections are maintained in many countries and by many institutions, including for instance the US's Harvard Brain Tissue Resource Centre, the UK Brain Bank Network and the Netherlands Brain Bank. There are also more specific collections of selected diseases such as The Mount Sinai School of Medicine Alzheimer's Disease and Schizophrenia Brain Bank in New York [36]. The BrainNet Europe consortium unites 19 countries with the aim of resolving the significant ethical and legal issues and providing bioethical principles to establish brain biobanking in Europe [37]. In 2018, at the Institute of Psychiatry and Neurology (IPiN) in Warsaw, a Digital Brain project (No. POPC.02.03.01-00.0042/18) was begun with the digitalisation of the resources of the Department of Neuropathology. More than 5,000 formalin-fixed brains and spinal cord samples, with paraffin blocks, microscopic specimens and clinical documentation, have been collected there since 1953 .

The collection of human brain tissue is essential in order to recognise new entities, as well as to explain clinical manifestations of diseases $[38,39]$. The newly recognised type of dementia, limbic-predominant age-related TDP-43 encephalopathy, is an excellent example of the practical utility of such research and collaboration $[32,38]$. Another aspect of biobanking includes the transmission of research conducted on well-designed animal models into human tissue, since most of these studies require validation on large brain post mortem cohorts [39].
Clinical, epidemiological, radiological and genetic studies combined with neuropathological analyses of large post mortem series are also important to guide public health policy, and minimise neurotoxicity and the environmental impact on the development of neurological disorders [40]. The focus on interdisciplinary approaches in order to maintain the high quality of these studies should be mentioned. Greater standardisation of brain post mortems is fundamental for extending the current knowledge of brain diseases [1,3]. The Association of Polish Neuropathologists, which gathers specialists in the fields of pathomorphology, neuropathology, neurology, neurosurgery and neurosciences, has recently updated its guidelines for post mortem examination of the central nervous system. These guidelines are aimed at the medical community, with the goal of updating the rules of conduct, emphasising the usefulness, promotion and revitalisation of CNS post mortems, and determining the cost-effectiveness and specificity of the procedure. It also indicates the need for functioning reference centres in the field of neuropathology. Presenting guidelines corresponds to regulations of Ministry of Health and Polish Society of Pathologist.

\section{Recommendation overview for CNS autopsy}

General and neuropathological post mortems should be performed in a dissecting room equipped with a standard set of tools and additional devices, with the safety and personal protection measures necessary when handling biological material and in the possible presence of high-risk infectious diseases. If a high-risk factor is known, precautions should be taken that are appropriate for the disease entity e.g. the skull should be opened, after covering inside a closed bag, using an oscillating saw under a wet towel, so as to reduce the formation of aerosol in patients with Creutzfeldt-Jakob Disease or COVID-19. Depending on the clinical diagnosis, either only the brain might be removed from the body, or the brain plus the spinal cord.

A general autopsy is performed at the request of a clinician, by a qualified physician who is either a specialist in the area of pathomorphology, or a resident under the supervision of a specialist. A neuropathological section should ideally be performed by a specialist in the field of neuropathology or a physician with experience in the evaluation of neuropathological tissue material. A lab technician performs preparatory, cleaning and sanitary activities regarding the body of the deceased and the post mortem room, and during the operation, auxiliary activities related to the removal of the brain and/or spinal cord, under the supervision and on the orders of the physician in charge.

Referral for an autopsy (autopsy card) is an internal document compliant with the health service's procedures and legal provisions, containing the following data: name, address, telephone number of the unit directing the procedure, patient identification data, data regarding the patient's stay in hospital 
including the date of admission to hospital, date and time of death, final clinical diagnosis, neuroimaging results and clinical resume, date of referral for post mortem, and finally the details, signature and stamp of the physician who made the referral. The medical history should be delivered before the general post mortem and be available for the neuropathological examination. It is highly recommended that the physician attend the autopsy.

\section{Scope of post mortem examination of brain and spinal cord}

A classical autopsy should encompass three body cavities, i.e. the skull, chest and abdominal cavity. Examinations of only the brain are allowed in cases of patients with CNS diseases, when the diagnostic tests performed during the patient's life have not revealed changes in other organs [3]. It is recommended to make photographic documentation, and/or select and describe changes in the CNS scheme. If it is technically possible, the section should be registered with a voice recorder and/or video camera, as well as hospital integrative systems [1].

The stages of the neuropathological examination during a general and neuropathological post mortem include external examination of the head and surrounding tissues, in situ examination, removal of the brain and possibly removal of the spinal cord, and their macroscopic examination including taking samples for histopathological and other tests [2, 40].

The technique of removing the brain and spinal cord includes several steps which have been described in detail in other publications. If cerebrospinal fluid needs to be taken, this procedure should be performed before removing the brain and/or spinal cord from the body [41].

In special cases, CNS can be evaluated actually during the post mortem, but normally this should be done after fixation in neutral buffered ( $\mathrm{pH} 7.0-7.2) 10 \%$ formalin for approximately 2-3 weeks. In certain special situations, short fixation is allowed, wherein it is recommended to make several sections and fix them in a flat position so as not to disturb the architecture. The brain should be put in a container filled with fixative in order to avoid deformation. The amount of fixative used should be 5-6 litres for the entire brain; it is recommended to change the fixative weekly. Brain samples should be fixed in a separate container with an appropriate amount of neutral buffered formalin (10 times the volume of the samples). Some pathological changes are visible in the brain only after complete or partial fixation. In these situations, without full brain fixation, significant problems can arise in terms of a proper macroscopic assessment $[1,4,17]$.

Brain cutting is most frequently performed according to Spielmeyer's method, starting with separation of the arachnoid mater and vessels of the circle of Willis, maintaining their arrangement and branches. The brainstem and cerebellum should be cut on the border with the cerebral peduncles. The brainstem should be cut off at the level of the substantia nigra and separated from the cerebellum by cutting the cerebellar peduncles, then the bottom of the fourth ventricle should be assessed. Cerebellar hemispheres should be cut through horizontally along the transverse groove. Midbrain, pons and medulla should be cut in the frontal plane into slices, c. $0.5 \mathrm{~cm}$ thick. Next, whole cerebral hemispheres should be sliced in the frontal plane into intervals of $1-1.5 \mathrm{~cm}$, starting from the frontal pole. To obtain parallel cutting planes, it is advantageous to use a glass plate, which should be applied to both hemispheres before the next cross-section, preventing their deformation. If the spinal cord is removed, it should be cut transversely to the long axis at intervals of $1 \mathrm{~cm}$ through the centre of the segment. All the slides should be arranged on an even flat surface, followed by proceeding to description, macroscopic assessment, photographic documentation, and collection of samples $[1,4,15]$.

The macroscopic description should include the weight of the brain, its general appearance (i.e. symmetry, deformations, the presence of herniation, oedema, the ratio of gyri to grooves, cortical atrophy) and the appearance of meninges (including the sinuses of dura mater), epidural spaces with particular emphasis on the presence of haemorrhages, assessment of cranial nerves, vascularisation (anatomical variants of vascularisation, malformation, degree of atherosclerosis) and the ventricular system (symmetry, content). In individual frontal sections, the structure, colour, coherence and outline of the cortex, white matter, hippocampus, basal ganglia, thalamus, insular cortex, midbrain, pons, medulla, cerebellum and spinal cord, as well as blurring of the boundary between the cortex and white matter, should all be assessed $[1,42]$.

\section{Rules for collecting samples for histopathological examination}

During a neuropathological autopsy, the brain is classified as either macroscopically normal or abnormal.

The term 'normal brain' refers to situations where the neurological history is negative, neuroimaging was normal or not performed, and the brain is macroscopically without pathological changes. Sections should be taken then from the frontal lobe with cingulate gyrus, superior and middle temporal gyri, parietal lobes, occipital gyri, putamen and globus pallidus, hippocampus, thalamus, periventricular white matter, midbrain, pons, cerebellar cortex with dentate nucleus (minimum 11 samples). If necessary, additional samples might be taken from available cervical spinal cord segments, intervertebral ganglia, medulla, mamillary bodies or other basal ganglia.

An 'abnormal brain' is a brain that is macroscopically altered or taken from patients with described neurological symptoms, with changes described in neuroimaging examinations, and from oncological patients, as well as in cases without an established cause of death. 
In the case of a normal brain, the samples might be taken from the brain without previous fixation. In fact, a post-fixation examination of an abnormal brain and spinal cord is recommended. Before performing the section of the fixed material, the brain should be rinsed under a gentle stream of cold running water for 1-2 hours.

The examination of 'abnormal brains' should always be considered in conjunction with medical history and neuroradiological imaging studies. Macroscopic examination should be performed according to general principles, with particular emphasis on the location of pathological changes and the implementation of appropriate photographic documentation or marking changes on cross-sectional views. In particular cases, the entire examination should be performed in a medical reference centre.

Samples from an 'abnormal brain' should be taken from macroscopically changed regions and, depending on the disease entity, clinical symptoms and the results of neuroimaging diagnostics should be collected in accordance with the algorithm of neuropathological diagnostics of a given disease entity $[6,13-15,18,19,21,22]$.

Specimens from both normal and abnormal brains should be marked with consecutive letters of the alphabet, e.g. right frontal lobe $A$, left parietal $B$, midbrain $C$ etc. and put into separate cassettes (marked with the case number and a letter corresponding to a particular structure). All samples should be then fixed in cassettes for about 24 hours, undergo routine histotechnological processing, and stained using the basic method i.e. haematoxylin-eosin (H\&E), and, if necessary, special histochemical, immunohistochemical or ultrastructural and molecular tests can then be performed [18, 43]. Specimens should be evaluated by a neuropathologist or pathologist.

\section{Ancillary studies}

Histochemical staining enables the identification and location of tissue and cellular components (proteins, enzymes, carbohydrates, microorganisms) based on their chemical structure [44]. The most commonly used techniques for neuron evaluation are cresyl violet stain and silver impregnation methods such as Bielschowsky or Bodian stains. Myelin sheaths are usually demonstrated by Spielmeyer, luxol fast blue or its variation, Kluver-Barrera stain. Congo red dye is used for amyloid depositions. Microorganisms are mostly visualised by PAS and Grocott staining [14, 16, 17, 43].

Immunohistochemistry is a method of detecting specific tissue antigens in microscopic sections using antibodies directed at sought-for elements/pathological proteins in tissues [45]. There are numerous antibodies used in diagnostic neuropathology including glial fibrillary acidic protein (GFAP), which is a marker of astrocytes, synaptophysin, S-100, neurofilament markers, LCA, CD68 of microglia, or EMA of meningeal cells $[17,18,43]$. Other highly specialised, non-commercial, and scientific antibodies are available only in dedicated centres in Poland and elsewhere.

In certain cases, molecular tests are performed where it may be necessary to secure fresh frozen material at an appropriate temperature. However, many genetic analyses can also be performed on material routinely preserved in paraffin blocks after fixing in formalin [17]. Molecular diagnosis is nowadays often essential for neuropathological examination. There are several clinicopathological entities where it is necessary to perform molecular tests and genetic diagnostics such as inherited/familial diseases, leukodystrophies, storage and metabolic disease, mitochondrial encephalopathies, neuromuscular disorders or triple nucleotide repeat disorders, etc. $[27,46,47]$. Moreover, molecular identification of various infectious agents may be necessary [48].

Securing and preparing material for microbiological, ultrastructural and toxicological tests should be consulted with the appropriate microbiology/toxicology/forensic laboratory in order to avoid pre-analytical errors. For instance, ultrastructure tests require the use of a fixative other than formalin, usually 2-5\% glutaraldehyde [1].

\section{Principles of sample collection for histopathological examination in basic clinical and pathological entities}

The number and types of samples (tissue sections) taken, and methods used, differ and can be individually variable; it can be as high as 40-50 in complex or coexisting diseases. Figures 1 and 2 set out the most important anatomical sites of sample acquisition. The general rules for collecting samples in the most common CNS disease entities are presented below. In all examples, the samples should be taken as complementary to the basic one referred to as 'normal brain' and described above.

\section{Vascular damage - CNS hypoxia/ischaemic and haemorrhagic stroke}

In the case of ischaemia of the CNS, sections should be taken, depending on the clinically predicted cause, from the area(s) most sensitive to hypoperfusion (i.e. hippocampus, cerebellar cortex, thalamus, midbrain), as well as watershed areas of cerebral and spinal vascular arteries (superior and middle frontal gyrus, superior and middle temporal gyrus, cingulate cortex, occipital gyri, putamen with globus pallidus, $\mathrm{T} 4$ vertebra). In addition, in the case of a macroscopically visible mass effect, additional samples from the pons, midbrain and medulla oblongata should be taken $[15,18,49]$.

In order to assess vascular changes in the course of a haemorrhagic or ischaemic stroke, a detailed macroscopic assessment is necessary, looking for cerebral venous sinus thrombosis, vascular malformations, aneurysms in the circle of Willis area and in the initial sections of the anterior, middle and posterior arteries; the atherosclerosis degree should be assessed. In addition, samples from the macroscopically visible 


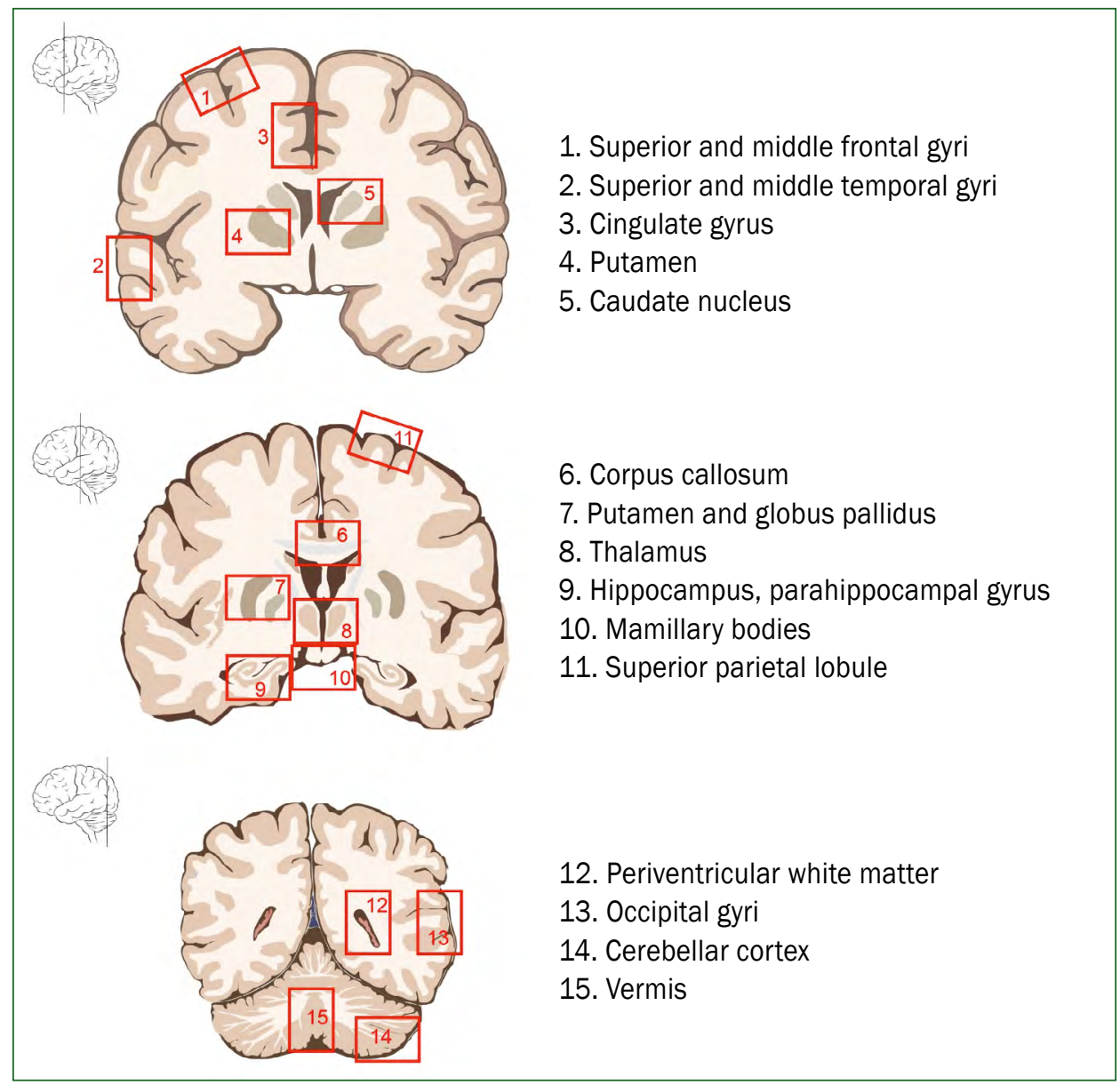

Figure 1.Scheme of sample acquisition according to anatomical localisation of most frequently injured sites in cerebrum

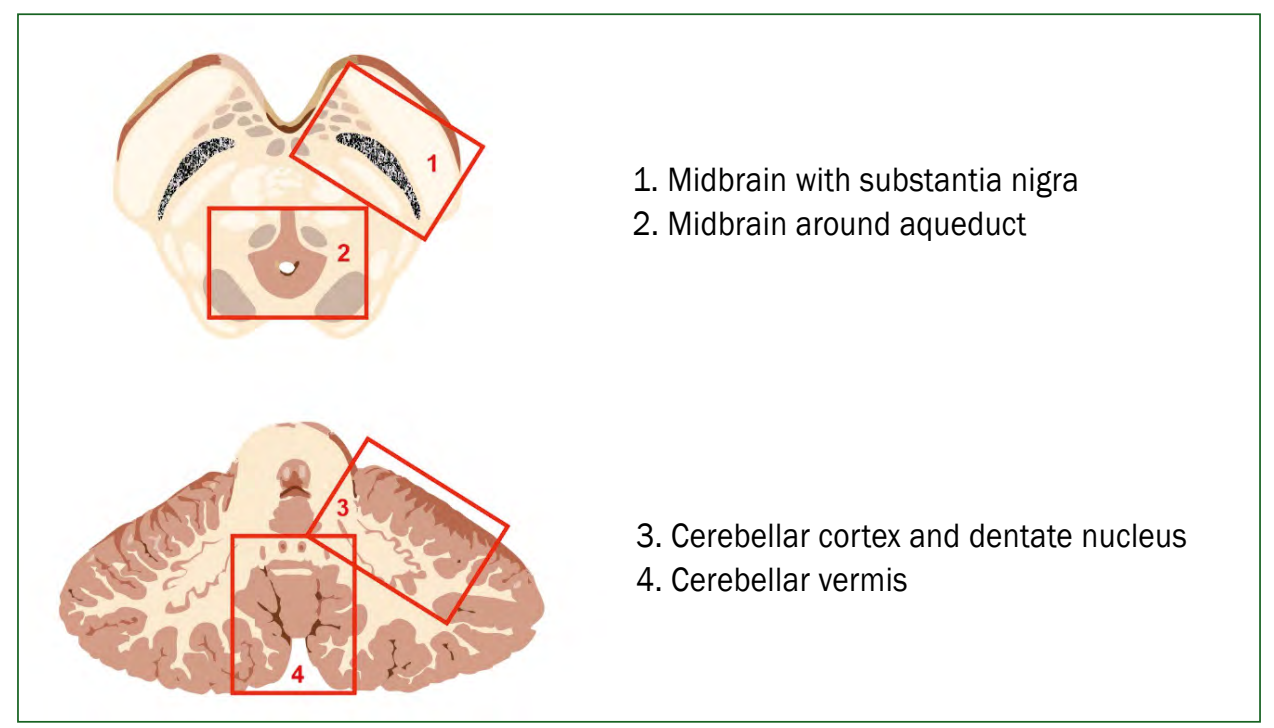

Figure 2. Scheme of sample acquisition according to anatomical localisation of most frequently injured sites in cerebellum and brainstem 
haemorrhagic and/or ischaemic focus should be taken each time to assess vascular lesions in the course of small vessel disease. Similarly, if a disease of large or small vessels is suspected, appropriate samples should be taken specific for each kind of disorder. In the case of lacunar stroke associated with hypertension and/or diabetes, samples should be taken from the globus pallidus, putamen and pons [18, 50-52].

To sum up, in total, a minimum of 11 sections (superior and middle frontal gyrus, superior and middle temporal gyrus, cingulate cortex, occipital gyri, putamen with globus pallidus, hippocampus, cerebellar cortex, thalamus, midbrain, and pons) should be taken for the assessment of ischaemic and haemorrhagic injuries without a clinical suspicion of a specific vascular disease. Table 1 shows the additional sample collection according to the most common CNS vascular pathologies $[14,15,18,50,51,81,82]$.

\section{Encephalitis, Infectious/ Inflammatory conditions}

In case of viral, bacterial, parasitic or autoimmune encephalitis, taking into account the macroscopic image, numerous samples should be taken from sites typical for a given infective agent. In the absence of pathogen identification, as a minimum, samples should be taken from the cortex of both hemispheres (always including those from the medial areas of both temporal lobes with hippocampi), from deep white and periventricular white matter, and from several levels of the brainstem, cerebellum, basal ganglia, paravertebral ganglia, meninges, and pituitary gland. This comprises a minimum of 11 sections, even up to 40 sections with strict topographic marking. Molecular or microbiological methods can be used on the samples to detect specific infective agents $[14,15,18,43]$.

\section{Neurodegenerative diseases}

Neurodegenerative diseases (NDs) constitute a heterogenous group of CNS diseases characterised by progressive neurological deficits associated with neuronal damage in specific anatomical areas, often accompanied by aggregation of incorrectly folded proteins $[18,21,53]$. Depending on the type of damaged and/or excessively stored protein and intracellular inclusions, observed mainly in neurons, but also in glial cells, among NDs we can distinguish tauopathies (most commonly Alzheimer's Disease, corticobasal degeneration, progressive supranuclear palsy, frontotemporal dementia and parkinsonism linked to chromosome 17), alpha-synucleinopathies (Parkinson's Disease, dementia with Lewy bodies, multiple system atrophy), trinucleotide repeat disorders (Huntington's Disease, spinocerebellar ataxia, Friedrich's ataxia, spinal muscular atrophy), prion diseases (Creutzfeldt-Jakob Disease, fatal familial insomnia, Gerstmann-Sträussler-Scheinker syndrome), and others $[18,54,55]$. In addition, in Alzheimer's Disease there are amyloid deposits made of amyloid beta, and in various subtypes of frontotemporal dementia there are intracellular inclusions of FUS proteins, TDP-43 or ubiquitin
Table 1. Recommended sample collection in common vascular disease of central nervous system (CNS)

\begin{tabular}{|c|c|}
\hline $\begin{array}{l}\text { Distinct vessel } \\
\text { disease }\end{array}$ & Samples \\
\hline Small vessel disease & \\
\hline $\begin{array}{l}\text { Cerebral amyloid } \\
\text { angiopathy }\end{array}$ & $\begin{array}{l}\text { Midfrontal and inferior temporal gyrus } \\
\text { (leptomeninges, superficial cerebral cortex } \\
\text { with subcortical white matter) } \\
\text { Calcarine cortices } \\
\text { Angular gyrus } \\
\text { Cerebellar cortex } \\
\text { Hippocampus }\end{array}$ \\
\hline $\begin{array}{l}\text { Churg-Strauss } \\
\text { syndrome (eosinophilic } \\
\text { granulomatosis with } \\
\text { polyangiitis) }\end{array}$ & $\begin{array}{l}\text { White matter } \\
\text { Watershed areas } \\
\text { Subcortical areas } \\
\text { Cortical areas }\end{array}$ \\
\hline Primary angiitis of CNS & $\begin{array}{l}\text { Samples from leptomeninges (especially } \\
\text { nondominant frontal lobe) } \\
\text { Superficial cerebral cortex }\end{array}$ \\
\hline $\begin{array}{l}\text { CADASIL (cerebral } \\
\text { autosomal dominant } \\
\text { arteriopathy with } \\
\text { subcortical infarcts and } \\
\text { leukoencephalopathy) }\end{array}$ & $\begin{array}{l}\text { Periventricular and deep white matter } \\
\text { Temporal lobe } \\
\text { Corpus callosum } \\
\text { Basal ganglia } \\
\text { External capsule } \\
\text { Brain stem } \\
\text { It is recommended to secure and fix at } \\
\text { least one fresh sample in glutaraldehyde } \\
\text { for ultrastuctural examination } \\
\text { Skin samples }\end{array}$ \\
\hline Chronic hypertension & $\begin{array}{l}\text { Putamen } \\
\text { Thalamus } \\
\text { Globus pallidus } \\
\text { Lobar deep white matter } \\
\text { Cerebellum } \\
\text { Pons }\end{array}$ \\
\hline Large vessel disease & \\
\hline Takayasu's arteritis & $\begin{array}{l}\text { Aortic arch } \\
\text { External and internal carotid arteries } \\
\text { Cerebral arteries }\end{array}$ \\
\hline Giant cell arteritis & $\begin{array}{l}\text { Temporal arteries } \\
\text { Vertebral arteries }\end{array}$ \\
\hline Fibromuscular dysplasia & $\begin{array}{l}\text { Internal carotid arteries } \\
\text { Vertebral arteries }\end{array}$ \\
\hline Moyamoya syndrome & $\begin{array}{l}\text { Circle of Willis } \\
\text { Internal carotid arteries and its branches } \\
\text { Anterior cerebral arteries } \\
\text { Middle cerebral arteries }\end{array}$ \\
\hline
\end{tabular}

Large vessel disease section include samples which should be taken from particular vessel wall

[56, 57]. In rarer NDs, such as amyotrophic lateral sclerosis, cytoplasmic inclusions (Bunina bodies) are present, consisting of the TDP43 protein, and in neurodegeneration with brain iron accumulation there are iron deposits mainly in the basal 
ganglia [23, 58]. Many, more or less typical, changes are connected to other entities.

The minimum 13 samples for the diagnosis of the most common neurodegenerative diseases include the middle frontal gyrus, cingulate cortex, superior and middle temporal gyrus, hippocampus with hippocampal gyrus and entorhinal cortex, superior parietal lobule, putamen with globus pallidus, midbrain, substantia nigra, pons, caudate nucleus, cerebellar vermis, cerebellar cortex with dentate nucleus, and medulla oblongata $[18,19,59]$.

In the case of $\mathrm{AD}$, a neuropathological assessment is performed according to the CERAD protocol (Consortium to Establish a Registry for Alzheimer's Disease), which assumes a semi-quantitative assessment of the number of senile plaques and neurofibrillary degeneration based on the examination of three neocortical areas $[24,54]$. Neuropathological staging of neurodegenerative disorders should be made according to Braak, the six-step scale depending on topographic distribution of neurofibrillary tangles [60]. In cases of other neurodegenerative diseases, samples should be taken in accordance with guidelines for specific clinical pathological units based on the literature $[13,23,26,60]$. Table 2 sets out information about sample collection in the most important neurodegenerative disorders [18, 60-63].

Apart from the routine H\&E stain, the sections are subjected to additional procedures. Most frequently, histochemical tests are performed to assess the degree of myelination and to detect senile plaques, neurophil threads, and neurofibrillary degeneration in specific areas (Bielschowsky silver staining/ Yamamoto's modification). In addition, depending on the type of dementia, immunohistochemical tests are performed to detect alpha-synuclein, Tau protein, amyloid beta, ubiquitin or $\operatorname{PrP}$ in prion diseases [13, 18, 56, 63, 64].

In the diagnosis of motoneuron diseases, samples are taken from each level of the spinal cord, peripheral nerves (good accessibility is to be found on the ankle halfway between the Achilles tendon and the lateral ankle, and the preferred fixation is in a buffered solution of glutaraldehyde) and muscles (sternocleidomastoid muscle, diaphragm, lumbar muscles) [19]. In neuromuscular diseases (myopathies, mitochondrial diseases, genetically determined diseases), necessary samples include proximal and distal limb muscles and the corresponding peripheral nerves, depending on the clinical picture. It must be remembered that in muscle and nerve diseases, the material often needs to be fixed fresh, or it requires special fixation and preparation. Therefore, before collecting the material, it is advisable to contact an appropriate referential centre $[1,65]$.

\section{Leukodystrophies and metabolic diseases}

Leukodystrophies constitute a group of about 100 genetically conditioned diseases involving white matter. In the case of brain post mortem of a patient with a diagnosed or suspected leukodystrophy, in addition to specimens typical for a normal brain, samples should be taken from subcortical and periventricular white matter of brain and cerebellum hemispheres, especially from macroscopically changed places and those described in the MRI as abnormal. However, a crucial role in metabolic disease diagnosis is played by molecular tests, as most of them are defined as genetically determined diseases with individual profiles $[27,66]$.

\section{Epilepsy}

In cases of patients with a history of epileptic seizures, especially with no known cause of death and a suspicion of sudden unexpected death in epilepsy (SUDEP), it is advisable to take samples from both hippocampi with entorhinal cortex, cingulate cortex, parahippocampal gyrus, middle temporal gyrus, middle frontal gyrus, caudate nucleus, putamen, globus pallidus, thalamus, cerebellar vermis, cerebellar hemispheres with dentate nucleus, and macroscopically visible lesions (minimum 12 samples) [67, 68].

\section{Endogenous and exogenous encephalopathies}

Endogenous encephalopathies constitute damage to the CNS in course of diseases of internal organs, e.g. cardiovascular, kidney, digestive or liver diseases, and paraneoplastic changes. Exogenous encephalopathies are most often caused by external factors such as vitamin deficiency, intoxication or poisoning, as well as injuries caused by environmental factors (about 8 extra samples, depending on the type of encephalopathy) $[14,18]$.

The most common exogenous injurious agent for CNS is alcohol. In patients with a history of alcohol dependence syndrome, taking into account clinical data and macroscopic images, additional samples should include corpus callosum, cerebellar hemispheres with cerebellar vermis (its upper and lower parts), mammillary bodies, periaqueductal grey matter, periventricular region, pons, and medulla oblongata $[18,69,70]$.

\section{Foetal and neonatal brain post mortem}

Foetal and neonatal brain post mortem is a special type of neuropathological examination. The provided medical documentation, apart from assessing the condition of the newborn and complications in the perinatal period, should be supplemented by information on the course of pregnancy, the mother's diseases, and any possible pathologies occurring in siblings or family [71]. In cases where it is necessary to assess the karyotype, material for cytogenetic testing should be taken, preferably from underarm skin. The scope of the procedure depends strictly on the foetal age.

Removal of the brain should begin with a cut around the skull, from the ear, through the occiput to the other ear, laterally to the neck area and towards the spine. Such a cut allows better access to the cervical spine in order to detect the presence of meningeal herniation, as well as to collect cerebrospinal fluid from the spinal canal. After removing 
Table 2. Detailed sample collection in particular neurodegenerative disorders

\begin{tabular}{|c|c|}
\hline $\begin{array}{l}\text { Type of neuro- } \\
\text { degeneration } \\
\text { disease }\end{array}$ & Samples \\
\hline \multicolumn{2}{|l|}{ Tauopathies } \\
\hline \multirow{14}{*}{$\begin{array}{l}\text { Alzheimer's } \\
\text { Disease (AD) }\end{array}$} & For Consortium to Establish a Registry for \\
\hline & Alzheimer's Disease protocol diagnosis of AD \\
\hline & Superior and middle temporal gyri \\
\hline & Middle frontal gyrus \\
\hline & Inferior parietal lobule \\
\hline & Anterior cingulate gyrus \\
\hline & Amygdala \\
\hline & Hippocampus and entorhinal cortex \\
\hline & Midbrain with substantia nigra \\
\hline & $\begin{array}{l}\text { For Braak stages determination (according to } \\
\text { BrainNet Europe Consortium) }\end{array}$ \\
\hline & $\begin{array}{l}\text { Occipital cortex including calcarine fissure and } \\
\text { peristriate/parastriate region }\end{array}$ \\
\hline & Superior and middle temporal gyri \\
\hline & $\begin{array}{l}\text { Posterior hippocampus at level of lateral } \\
\text { geniculate nucleus }\end{array}$ \\
\hline & Anterior hippocampus at level of uncus \\
\hline \multirow{9}{*}{$\begin{array}{l}\text { Progressive } \\
\text { supranuclear } \\
\text { palsy }\end{array}$} & $\begin{array}{l}\text { Midbrain with substantia nigra, periaqueductal } \\
\text { grey matter and red nucleus }\end{array}$ \\
\hline & Pons with locus coeruleus \\
\hline & Subthalamic nucleus \\
\hline & Globus pallidus \\
\hline & Striatum \\
\hline & Hippocampus \\
\hline & Medulla with inferior olivary nucleus \\
\hline & Dentate nucleus of cerebellum \\
\hline & Frontal cortex \\
\hline \multirow{13}{*}{$\begin{array}{l}\text { Corticobasal } \\
\text { degeneration }\end{array}$} & Superior frontal gyri \\
\hline & Superior parietal lobule \\
\hline & Superior temporal gyrus \\
\hline & Hippocampus with entorhinal cortex \\
\hline & Amygdala \\
\hline & Striatum \\
\hline & Globus pallidus \\
\hline & Thalamus \\
\hline & Subthalamic nucleus \\
\hline & $\begin{array}{l}\text { Midbrain with substantia nigra, tectum and red } \\
\text { nucleus }\end{array}$ \\
\hline & Pons with locus coeruleus \\
\hline & Medulla with inferior olivary nucleus \\
\hline & Dentate nucleus of cerebellum \\
\hline
\end{tabular}

the scalp, measure the fontanelle, assess its tension, and examine the cranial bones. Next, open the cranial cavity by making cuts along the cranial bone suture lines, starting from the anterior fontanelle region forward and backward, and then elliptically along the base of the skull. At this stage, the presence of intracranial bleeding and the appearance

\begin{tabular}{|c|c|}
\hline $\begin{array}{l}\text { Type of neuro- } \\
\text { degeneration } \\
\text { disease }\end{array}$ & Samples \\
\hline $\begin{array}{l}\text { Frontotemporal } \\
\text { dementia and } \\
\text { parkinsonism } \\
\text { linked to } \\
\text { chromosome } 17\end{array}$ & $\begin{array}{l}\text { Frontal and temporal cortex } \\
\text { Caudate nucleus } \\
\text { Putamen } \\
\text { Globus pallidus } \\
\text { Amygdala } \\
\text { Hippocampus } \\
\text { Cerebellar cortex } \\
\text { Midbrain } \\
\text { Pons }\end{array}$ \\
\hline $\begin{array}{l}\text { Unified Staging } \\
\text { System for } \\
\text { Lewy Body } \\
\text { disorders } \\
\text { (Dementia with } \\
\text { Lewy bodies, } \\
\text { PD, AD) }\end{array}$ & $\begin{array}{l}\text { Olfactory bulb } \\
\text { Medulla at level of IXth and Xth cranial nerves } \\
\text { Pons at level of locus coeruleus } \\
\text { Midbrain at level of IIIrd cranial nerve } \\
\text { Amygdala through its midpoint } \\
\text { Transentorhinal area adjacent to amygdala } \\
\text { Anterior cingulate gyrus } \\
\text { Middle temporal gyrus } \\
\text { Inferior parietal lobule } \\
\text { Middle frontal gyrus }\end{array}$ \\
\hline Other alpha-synu & leinopathies \\
\hline $\begin{array}{l}\text { Multiple system } \\
\text { atrophy }\end{array}$ & $\begin{array}{l}\text { Putamen } \\
\text { Globus pallidus } \\
\text { Pons } \\
\text { Midbrain with substantia nigra } \\
\text { Medulla with inferior olivary nucleus } \\
\text { Caudate }\end{array}$ \\
\hline Trinucleotide Rep & at Diseases \\
\hline $\begin{array}{l}\text { Huntington's } \\
\text { Disease }\end{array}$ & $\begin{array}{l}\text { For Vonsattel staging evaluation samples from } \\
\text { three brain levels: } \\
\text { CAP level (caudate, accumbens, putamen anterior } \\
\text { to rostral globus pallidus) } \\
\text { Level of globus pallidus } \\
\text { Tail of caudate nucleus (with hippocampus) at } \\
\text { level of lateral geniculate body }\end{array}$ \\
\hline $\begin{array}{l}\text { Frontotemporal } \\
\text { lobar } \\
\text { degeneration } \\
\text { (FTLD) }\end{array}$ & $\begin{array}{l}\text { Middle frontal gyrus } \\
\text { Superior temporal gyrus } \\
\text { Parietal lobe } \\
\text { Hippocampus } \\
\text { Cingulate gyrus } \\
\text { Striatum } \\
\text { Medulla }\end{array}$ \\
\hline
\end{tabular}

and continuity of the dura mater are assessed. An incision of the cerebral falx is then made and both hemispheres of the brain are removed. The removal of the cerebellum takes place after cutting the cerebellar tentorium. The cervical spinal cord should be cut through the foramen magnum as deeply as possible $[41,72]$. 
After removing the entire brain, it should be weighed and placed in a container filled with a fixative solution for c.720 days. This is particularly important when hydrocephalus, intracerebral bleeding or holoprosencephaly are suspected. In a situation where early post mortem lesions are suspected, attempts can be made to fix the brain inside the skull by injecting formalin solution into the subdural space with a syringe and a small amount into the ventricular system through the posterior commissure. After this time, macroscopic and microscopic assessments should be performed, paying particular attention to the presence of malformations, perinatal injuries, and prematurity complications (germinal matrix haemorrhage, periventricular leukomalacia). The hemispheres of the brain, brainstem and cerebellum should be cut serially in the frontal plane into slices no larger than $1 \mathrm{~cm}$ in diameter $[1,71,72]$.

Where there is clinical suspicion of neonatal hypoxia, a minimum of 10 samples should be taken from the cerebral cortex and periventricular white matter of both hemispheres, deep grey matter (thalamus, basal ganglia), hippocampus, midbrain, pons, medulla oblongata at the level of the olivary bodies, and cerebellum with dentate nucleus [73]. If congenital malformations are found, it is recommended to collect a large number of specimens from different brain regions, depending on the types of malformation present.

If it is necessary to perform a spinal cord section, removal of the spinal cord and its assessment are performed as would be the case in adults, usually from an anterior approach $[1,4,71]$.

\section{Brain autopsy in suspected prion disease}

Particular caution is needed when performing a brain post mortem if prion disease is suspected, since the central nervous system has the highest degree of infectivity in prion diseases [59]. Post mortems and the processing of non-decontaminated tissues should take place in a laboratory with a biosafety level of 2 or higher [74]. Tools should be disposable or, if this is not possible, they should be decontaminated [75]. Before the brain is fixed, at least one brain fragment from the frontal cortex and cerebellum should be taken to obtain fresh frozen material for biochemical and genetic testing [59].

The neuropathological autopsy in this particular case is carried out routinely. Recommended specimens for collection are one fragment of the frontal, parietal, occipital and temporal cortex, hippocampus, basal ganglia, thalamus, midbrain, cerebellum and medulla oblongata, since the distribution of lesions can be of different intensities in different CNS regions (minimum 10 samples). In selected specimens, immunohistochemistry detecting the pathological form of prion protein (PrPSc) should be performed. Since most of the available anti-PrP antibodies do not allow the pathological isoform to be distinguished, a procedure combining an autoclave with dipping the specimens in a $96 \%$ solution of formic acid can be utilised, or the proteinase K protocol [76-78].
Particular caution should be exercised if a variant of Creutzfeldt-Jakob Disease (vCJD) is suspected, because in addition to the nervous system, high infectivity also affects the lymphatic system and blood. In the case of palatine tonsil biopsy, which is used as a diagnostic method when vCJD is suspected, one should proceed similarly as in the case of brain biopsy [76].

\section{Other CNS diseases}

Besides the ones mentioned above, there are numerous CNS conditions such as tumours or demyelinating diseases which affect nervous tissue. Post mortems in these particular cases should be performed individually according to the specific protocols usually in place regarding clinical data and radiological examination.

\section{Forensic autopsy}

Due to significant differences in the performance of forensic autopsy of the brain, they should be carried out by a forensic doctor in consultation with a neuropathologist. The scope of such a post mortem is determined by the relevant recommendations in forensic medicine [79]. A forensic autopsy is performed when there is a reasonable suspicion that death did not occur due to natural causes, but rather with the participation of third parties, or to ensure that the cause of death was natural. Autopsy is carried out at the request of the prosecutor's office or the court when there is a suspicion of homicide, as well as in cases of violent death. The most common neuropathological issues in forensic medicine are post-traumatic CNS changes, intoxication, as well as vascular and hypoxic changes. Due to the purpose of a forensic examination, individualised methods of opening the skull and securing tissue material are often used $[79,80]$.

\section{Post mortem neuropathological examination protocol and quality control}

According to Regulation of the Minister of Health (Dz.U. 2015 poz. 2069., DZ. URZ. Min. Zdr. 2021.75) the result of the brain and spinal cord post mortem examination is described in the post mortem protocol, containing the data of the patient and the referring department, clinical diagnosis, a macroscopic neuropathological diagnosis together with a macroscopic description, and the result of the histopathological examination with additional methods and conclusions from the examination. A complete post mortem report should be available to the unit commissioning the post mortem within 30 days in cases of average diagnostic difficulty, and within 60 days in complicated cases [83]. Sometimes, the case requires consultation or additional tests at another centre, and this prolongs the process. 
Tissue material collected during the section and the brain fixed in formalin should be stored for a minimum of three months from the issuing of the protocol (in units without an archive of formalin specimens). The storage period of paraffin blocks and microscope slides should be consistent with the relevant Regulation of the Minister of Health regarding storage of medical records (Dz. U. 2015 poz. 2069).

The results of the neuropathological post mortem examination, the final summary of which is contained in the post mortem protocol, should be discussed at appropriate consultation meetings (e.g. neurological meetings, in-hospital mortality conferences) giving the opportunity to discuss clinical diagnoses with pathological data and thus correctly diagnose the cause of death, also for the purposes of administration. In addition, the functioning of existing neuropathological reference centres should be supported, and consideration should be given to the creation of multicentre pathoclinical databases in the field of neurology and neuropathology for statistical purposes, environmental research, and genetic counselling.

As part of ensuring the high quality neuropathological services, it is recommended in pathomorphology/neuropathology centres to follow the recommendations/procedures of the hospital, the Polish Society of Pathologists, and the Association of Polish Neuropathologists. Every major pathomorphology facility, if it does not employ a neuropathologist, is advised to train, or enable the training of, a selected doctor in the field of neuropathology. It is recommended that in difficult cases material be sent for consultative examination by a qualified neuropathologist.

\section{Conclusions and future directions}

The guidelines discussed above have been developed by the Polish Association of Neuropathologists, comprising neuropathologists, neurologists and pathomorphologists dealing with this subject matter and having experience in the field of brain and spinal cord post mortems. The proposed standards are based on our own experience and good practice, the recommendations of scientific societies from European Union countries and the United States, as well as the available literature. The recommendations are aimed at standardising the procedures regarding post mortem examinations of the brain and spinal cord, the handling of tissue material and the method of formulating protocols and results of this examination in Poland. The guidelines also define the basis for pathoclinical and administrative cooperation, and introduce the current standard and quality control tool of neuropathological post mortems.

Due to constantly evolving neuroscientific research, it is necessary to correlate clinical diagnosis with brain tissue examination as well as to introduce standards for proper post mortem evaluation of CNS.

Therefore, we emphasise the necessity of conducting brain autopsies in clinical context, the formation of brain banks, the elaboration of standardised diagnostic protocols, and the creation of on-line databases and continuous education of medical staff.

Conflict of interest: None.

Funding: None.

\section{References}

1. Powers JM. Practice guidelines for autopsy pathology. Autopsy procedures for brain, spinal cord, and neuromuscular system. Autopsy Committee of the College of American Pathologists. Arch Pathol Lab Med. 1995; 119(9): 777-783, indexed in Pubmed: 7668934.

2. The Royal College of Pathologists. Guidelines on autopsy practice. Report of a working group of The Royal College of Pathologists London, 2002.

3. Kuijpers CC, Fronczek J, van de Goot FRW, et al. The value of autopsies in the era of high-tech medicine: discrepant findings persist. J Clin Pathol. 2014; 67(6): 512-519, doi: 10.1136/jclinpath-2013-202122, indexed in Pubmed: 24596140.

4. Iacono D, Geraci-Erck M, Peng H, et al. Symmetric bihemispheric postmortem brain cutting to study healthy and pathological brain conditions in humans. J Vis Exp. 2016(118): 54602, doi: 10.3791/54602, indexed in Pubmed: 28060309.

5. Javier Meana J, Callado LF, Morentin B. [Do post-mortem brain studies provide useful information for psychiatry?]. Rev Psiquiatr Salud Ment. 2014; 7(3): 101-103, doi: 10.1016/j.rpsm.2014.05.001, indexed in Pubmed: 24996401.

6. King A, Maekawa S, Bodi I, et al. Simulated surgical-type cerebral biopsies from post-mortem brains allows accurate neuropathological diagnoses in the majority of neurodegenerative disease groups. Acta Neuropathol Commun. 2013; 1: 53, doi: 10.1186/2051-5960-1-53, indexed in Pubmed: 24252649.

7. Roulson J, Benbow EW, Hasleton PS. Discrepancies between clinical and autopsy diagnosis and the value of post mortem histology; a meta-analysis and review. Histopathology. 2005; 47(6): 551-559, doi: 10.1111/j.1365-2559.2005.02243.x, indexed in Pubmed: 16324191.

8. Grinberg LT, Amaro E, Teipel S, et al. Brazilian Aging Brain Study Group. Assessment of factors that confound MRI and neuropathological correlation of human postmortem brain tissue. Cell Tissue Bank. 2008; 9(3): 195-203, doi: 10.1007/s10561-008-9080-5, indexed in Pubmed: 18548334.

9. Kansal K, Irwin DJ. The use of cerebrospinal fluid and neuropathologic studies in neuropsychiatry practice and research. Psychiatr Clin North Am. 2015; 38(2): 309-322, doi: 10.1016/j.psc.2015.02.002, indexed in Pubmed: 25998118.

10. Wiley C, Hart MN, Weidenheim KM, et al. Examining neuropathology: beginning a dialogue. J Neuropathol Exp Neurol. 2016; 75(12): 11791183, doi: 10.1093/jnen/nlw091, indexed in Pubmed: 27941138.

11. Blokker BM, Weustink AC, Wagensveld IM, et al. Conventional autopsy versus minimally invasive autopsy with postmortem MRI, CT, and CT-guided biopsy: comparison of diagnostic performance. Radiology. 2018; 289(3): 658-667, doi: 10.1148/radiol.2018180924, indexed in Pubmed: 30251930.

12. Joseph TI, Girish KL, Sathyan P, et al. Virtopsy: an integration of forensic science and imageology. J Forensic Dent Sci. 2017; 9(3): 111114, doi: 10.4103/jfo.jfds_52_16, indexed in Pubmed: 29657485.

13. Love S. Neuropathological investigation of dementia: a guide for neurologists. J Neurol Neurosurg Psychiatry. 2005; 76(Suppl 5): v8-v14, doi: 10.1136/jnnp.2005.080754, indexed in Pubmed: 16291923. 
14. Liberski P, Papierz W. Neuropatologia Mossakowskiego. Czelej, Lublin 2005.

15. Gray F, Duyckaerts C, Girolami U. Escourolle \& Poirier Manual of Basic Neuropathology. 6th edition. Oxford University Press 2018.

16. Mossakowski M, Dymecki J, Wender M. Podstawy neuropatologii. PZWL, Warszawa 1981.

17. Alafuzoff I. Techniques in neuropathology. Handbook of Clinical Neurology. 2018; 145: 3-7, doi: 10.1016/b978-0-12-802395-2.00001-8.

18. Ellison D, Love S, Chimelli LC, Harding B, Lowe J, Vinters HV. Neuropathology: Reference Text of CNS Pathology. 3rd ed. Elsevier, Amsterdam 2013.

19. Love S. Post mortem sampling of the brain and other tissues in neurodegenerative disease. Histopathology. 2004; 44(4): 309-317, doi: 10.1111/j.1365-2559.2004.01794.x, indexed in Pubmed: 15049895.

20. Ubhi K, Low P, Masliah E. Multiple system atrophy: a clinical and neuropathological perspective. Trends Neurosci. 2011; 34(11): 581-590, doi: 10.1016/j.tins.2011.08.003, indexed in Pubmed: 21962754.

21. Dugger BN, Dickson DW. Pathology of neurodegenerative diseases. Cold Spring Harb Perspect Biol. 2017; 9(7): a028035, doi: 10.1101/ cshperspect.a028035, indexed in Pubmed: 28062563.

22. Filippi M, Brück W, Chard D, et al. Association between pathological and MRI findings in multiple sclerosis. Lancet Neurol. 2019; 18(2): 198-210, doi: 10.1016/s1474-4422(18)30451-4, indexed in Pubmed: 30663609.

23. Pallebage-Gamarallage M, Foxley S, Menke RAL, et al. Dissecting the pathobiology of altered MRI signal in amyotrophic lateral sclerosis: a post mortem whole brain sampling strategy for the integration of ultra-high-field MRI and quantitative neuropathology. BMC Neurosci. 2018; 19(1): 11, doi: 10.1186/s12868-018-0416-1, indexed in Pubmed: 29529995.

24. Besser LM, Kukull WA, Teylan MA, et al. The revised national alzheimer's coordinating center's neuropathology form-available data and new analyses. J Neuropathol Exp Neurol. 2018; 77(8): 717-726, doi: 10.1093/jnen/nly049, indexed in Pubmed: 29945202.

25. Nelson PT, Alafuzoff I, Bigio EH, et al. Correlation of Alzheimer disease neuropathologic changes with cognitive status: a review of the literature. J Neuropathol Exp Neurol. 2012; 71(5): 362-381, doi: 10.1097/ NEN.0b013e31825018f7, indexed in Pubmed: 22487856.

26. De Pablo-Fernández E, Lees AJ, Holton JL, et al. Prognosis and neuropathologic correlation of clinical subtypes of parkinson disease. JAMA Neurol. 2019; 76(4): 470-479, doi: 10.1001/jamaneurol.2018.4377, indexed in Pubmed: 30640364.

27. van der Knaap MS, Bugiani M. Leukodystrophies: a proposed classification system based on pathological changes and pathogenetic mechanisms. Acta Neuropathol. 2017; 134(3): 351-382, doi: 10.1007/ s00401-017-1739-1, indexed in Pubmed: 28638987.

28. Matej R, Tesar A, Rusina R. Alzheimer's disease and other neurodegenerative dementias in comorbidity: a clinical and neuropathological overview. Clin Biochem. 2019; 73: 26-31, doi: 10.1016/j.clinbiochem.2019.08.005, indexed in Pubmed: 31400306.

29. Josephson SA, Papanastassiou AM, Berger MS, et al. The diagnostic utility of brain biopsy procedures in patients with rapidly deteriorating neurological conditions or dementia. J Neurosurg. 2007; 106(1): $72-$ 75, doi: 10.3171/jns.2007.106.1.72, indexed in Pubmed: 17236490.

30. Ravid R, Ikemoto K. Pitfalls and practicalities in collecting and banking human brain tissues for research on psychiatric and neulogical disorders. Fukushima J Med Sci. 2012; 58(1): 82-87, doi: 10.5387/ fms.58.82, indexed in Pubmed: 22790897.
31. Haroutunian V, Pickett J. Autism brain tissue banking. Brain Pathol. 2007; 17(4): 412-421, doi: 10.1111/j.1750-3639.2007.00097.x, indexed in Pubmed: 17919127.

32. Josephs KA, Murray ME, Tosakulwong N, et al. Pathological, imaging and genetic characteristics support the existence of distinct TDP-43 types in non-FTLD brains. Acta Neuropathol. 2019; 137(2): 227-238, doi: 10.1007/s00401-018-1951-7, indexed in Pubmed: 30604226.

33. Sieracka J, Sieracki P, Kozera G, et al. COVID-19 - neuropathological point of view, pathobiology, and dilemmas after the first year of the pandemic struggle. Folia Neuropatol.2021;59(1):1-16, doi:10.5114/ fn.2021.105128, indexed in Pubmed: 33969672.

34. Shepherd CE, Alvendia H, Halliday GM. Brain banking for research into neurodegenerative disorders and ageing. Neurosci Bull. 2019; 35(2): 283288, doi: 10.1007/s12264-018-0326-3, indexed in Pubmed: 30604281.

35. Carlos AF, Poloni TE, Medici V, et al. From brain collections to modern brain banks: a historical perspective. Alzheimers Dement (N Y). 2019; 5: 52-60, doi: 10.1016/j.trci.2018.12.002, indexed in Pubmed: 30775417.

36. Deep-Soboslay A, Benes FM, Haroutunian V, et al. Psychiatric brain banking: three perspectives on current trends and future directions. Biol Psychiatry. 2011; 69(2): 104-112, doi: 10.1016/j.biopsych.2010.05.025, indexed in Pubmed: 20673875.

37. Klioueva NM, Rademaker MC, Huitinga I. Design of a European code of conduct for brain banking. Handb Clin Neurol. 2018; 150: 51-81, doi: 10.1016/B978-0-444-63639-3.00005-0, indexed in Pubmed: 29496156.

38. Nelson PT, Dickson DW, Trojanowski JQ, et al. Limbic-predominant age-related TDP-43 encephalopathy (LATE): consensus working group report. Brain. 2019; 142(6): 1503-1527, doi: 10.1093/brain/ awz099, indexed in Pubmed: 31039256.

39. Kretzschmar H. Brain banking: opportunities, challenges and meaning for the future. Nat Rev Neurosci. 2009; 10(1): 70-78, doi: 10.1038/ nrn2535, indexed in Pubmed: 19050713.

40. Hill RB, Anderson RE. The autopsy - medical practice and public policy. Elsevier, Amsterdam 2016.

41. Fyfe-Kirschnerm B, Miller DV. Diagnostic pathology: hospital autopsy. Elsevier, Amsterdam 2015.

42. Moryś J, Narkiewicz 0. Neuroanatomia czynnościowa i kliniczna. PZWL, Warszawa 2020.

43. Perry A, Brat D. Practical surgical neuropathology: a diagnostic approach. A volume in the pattern recognition series. 2nd ed. Elsevier, Amsterdam 2017.

44. Pellicciari C. Histochemistry as a versatile research toolkit in biological research, not only an applied discipline in pathology. Eur J Histochem. 2018; 62(4), doi: 10.4081/ejh.2018.3006, indexed in Pubmed: 30572698.

45. Kim SW, Roh J, Park CS. Immunohistochemistry for pathologists: protocols, pitfalls, and tips. J Pathol Transl Med. 2016; 50(6): 411-418, doi: 10.4132/jptm.2016.08.08, indexed in Pubmed: 27809448.

46. Molnar MJ, Kovacs GG. Mitochondrial diseases. Handb Clin Neurol. 2017; 145: 147-155, doi: 10.1016/B978-0-12-802395-2.00010-9, indexed in Pubmed: 28987165.

47. Paulson H. Repeat expansion diseases. Handb Clin Neurol. 2018; 147: 105-123, doi: 10.1016/B978-0-444-63233-3.00009-9, indexed in Pubmed: 29325606.

48. Conejero-Goldberg C, Wang E, Yi C, et al. Infectious pathogen detection arrays: viral detection in cell lines and postmortem brain tissue. Biotechniques. 2005; 39(5): 741-751, doi: 10.2144/000112016, indexed in Pubmed: 16312221. 
49. Love S. Autopsy approach to stroke. Histopathology. 2011; 58(3): 333-351, doi: 10.1111/j.1365-2559.2010.03614.x, indexed in Pubmed: 20666847.

50. Samson M, Jacquin A, Audia S, et al. Stroke associated with giant cell arteritis: a population-based study. J Neurol Neurosurg Psychiatry. 2015; 86(2): 216-221, doi: 10.1136/jnnp-2014-307614, indexed in Pubmed: 24780954.

51. Søndergaard CB, Nielsen JE, Hansen CK, et al. Hereditary cerebral small vessel disease and stroke. Clin Neurol Neurosurg. 2017; 155: 45-57, doi: 10.1016/j.clineuro.2017.02.015, indexed in Pubmed: 28254515.

52. Planas AM. Top ten discoveries of the year: neurovascular disease. Free Neuropathology. 2020; 1: 5, doi: 10.17879/freeneuropathology-2020-2615.

53. Armstrong R. What causes neurodegenerative disease? Folia Neuropathol. 2020; 58(2): 93-112, doi: 10.5114/fn.2020.96707, indexed in Pubmed: 32729289.

54. Dickson D, Roy W. Neurodegeneration: the molecular pathology of dementia and movement disorders. 2nd ed. Wiley-Blackwell, Jacksonville 2011.

55. Kovacs GG. Molecular pathological classification of neurodegenerative diseases: turning towards precision medicine. Int J Mol Sci. 2016; 17(2), doi: 10.3390/ijms17020189, indexed in Pubmed: 26848654.

56. Raz L, Knoefel J, Bhaskar K. The neuropathology and cerebrovascular mechanisms of dementia. J Cereb Blood Flow Metab. 2016; 36(1): 172 186, doi: 10.1038/jcbfm.2015.164, indexed in Pubmed: 26174330.

57. Armstrong RA. On the 'classification' of neurodegenerative disorders: discrete entities, overlap or continuum? Folia Neuropathol. 2012; 50(3): 201-208, doi: 10.5114/fn.2012.30521, indexed in Pubmed: 23023335.

58. Schneider SA. Neurodegeneration with brain iron accumulation. Curr Neurol Neurosci Rep. 2016; 16(1): 9, doi: 10.1007/s11910-0150608-3, indexed in Pubmed: 26739693.

59. The Royal College of Pathologists. Neuropathology autopsy practice: post-mortem examination in dementia. London, September 2014.

60. Alafuzoff I, Arzberger T, Al-Sarraj S, et al. Staging of neurofibrillary pathology in Alzheimer's disease: a study of the BrainNet Europe Consortium. Brain Pathol. 2008; 18(4): 484-496, doi: 10.1111/j.1750-3639.2008.00147.x, indexed in Pubmed: 18371174.

61. Halliday GM, Holton JL, Revesz T, et al. Neuropathology underlying clinical variability in patients with synucleinopathies. Acta Neuropathol. 2011; 122(2): 187-204, doi: 10.1007/s00401-011-0852-9, indexed in Pubmed: 21720849.

62. Vonsattel JP, Myers RH, Stevens TJ, et al. Neuropathological classification of Huntington's disease. J Neuropathol Exp Neurol. 1985; 44(6): 559-577, doi: 10.1097/00005072-198511000-00003, indexed in Pubmed: 2932539.

63. Cairns NJ, Bigio EH, Mackenzie IRA, et al. Consortium for Frontotemporal Lobar Degeneration. Neuropathologic diagnostic and nosologic criteria for frontotemporal lobar degeneration: consensus of the Consortium for Frontotemporal Lobar Degeneration. Acta Neuropathol. 2007; 114(1): 5-22, doi: 10.1007/s00401-007-0237-2, indexed in Pubmed: 17579875.

64. Crary JF. Top ten discoveries of the year: neurodegeneration. Free Neuropathology. 2020; 1: 12, doi: 10.17879/freeneuropathology-2020-2634.

65. Margeta M. Top ten discoveries of the year: neuromuscular disease. Free Neuropathology. 2020; 1: 4, doi: 10.17879/freeneuropathology-2020-2627.
66. Freeman SH, Hyman BT, Sims KB, et al. Adult onset leukodystrophy with neuroaxonal spheroids: clinical, neuroimaging and neuropathologic observations. Brain Pathol. 2009; 19(1): 39-47, doi: 10.1111/j.1750-3639.2008.00163.x, indexed in Pubmed: 18422757.

67. Thom M, Boldrini M, Bundock E, et al. Review: The past, present and future challenges in epilepsy-related and sudden deaths and biobanking. Neuropathol Appl Neurobiol. 2018; 44(1): 32-55, doi: 10.1111/ nan.12453, indexed in Pubmed: 29178443.

68. Aronica E, Mühlebner A. Neuropathology of epilepsy. Handb Clin Neurol. 2017; 145: 193-216, doi: 10.1016/B978-0-12-802395-2.000158, indexed in Pubmed: 28987170.

69. Sutherland GT, Sheedy D, Kril JJ. Neuropathology of alcoholism. Handb Clin Neurol. 2014; 125: 603-615, doi: 10.1016/B978-0-44462619-6.00035-5, indexed in Pubmed: 25307599.

70. Harper C. The neuropathology of alcohol-related brain damage. Alcohol Alcohol. 2009; 44(2): 136-140, doi: 10.1093/alcalc/agn102, indexed in Pubmed: 19147798.

71. Putman MA. Perinatal perimortem and postmortem examination: obligations and considerations for perinatal, neonatal, and pediatric clinicians. Adv Neonatal Care. 2007; 7(6): 281-288, doi: 10.1097/01. ANC.0000304966.39084.26, indexed in Pubmed: 18097209.

72. Jaiman S. Performing a perinatal autopsy. Journal of Fetal Medicine. 2015; 2(3): 101-111, doi: 10.1007/s40556-015-0059-6.

73. The Royal College of Pathologists. Guidelines on autopsy practice: Fetal autopsy (2nd trimester fetal loss and termination of pregnancy for congenital anomaly). London, June 2017.

74. Biosafety in microbiological and iomedical laboratories. 5th ed. September 2009.

75. Rutala WA, Weber DJ. Creutzfeldt-Jakob disease: recommendations for disinfection and sterilization. Clin Infect Dis. 2001; 32(9): 13481356, doi: 10.1086/319997, indexed in Pubmed: 11303271.

76. Ironside JW, Ritchie DL, Head MW. Prion diseases. Handb Clin Neurol. 2018; 145: 393-403, doi: 10.1016/b978-0-12-802395-2.00028-6, indexed in Pubmed: 28987186.

77. Ritchie DL, Ironside JW. Neuropathology of Human Prion Diseases. Prog Mol Biol Transl Sci. 2017; 150: 319-339, doi: 10.1016/ bs.pmbts.2017.06.011, indexed in Pubmed: 28838666.

78. Kovacs G. Neuropathology of neurodegenerative diseases. A practical guide. Cambridge University Press 2014.

79. Kalimo H, Saukko P, Graham D. Neuropathological examination in forensic context. Forensic Sci Int. 2004; 146(2-3): 73-81, doi: 10.1016/j.forsciint.2004.06.022, indexed in Pubmed: 15542266.

80. Mckee AC, Abdolmohammadi B, Stein TD. The neuropathology of chronic traumatic encephalopathy. Handb Clin Neurol. 2018; 158: 297-307, doi: 10.1016/b978-0-444-63954-7.00028-8, indexed in Pubmed: 30482357.

81. Arvanitakis Z, Leurgans SE, Wang Z, et al. Cerebral amyloid angiopathy pathology and cognitive domains in older persons. Ann Neurol. 2011; 69(2): 320-327, doi: 10.1002/ana.22112, indexed in Pubmed: 21387377.Beuker C, Schmidt A, Strunk D, et al.

82. Primary angiitis of the central nervous system: diagnosis and treatment. Ther Adv Neurol Disord. 2018; 11: 1756286418785071, doi: 10.1177/1756286418785071, indexed in Pubmed: 30034536.

83. Polskie Towarzystwo Patologów. Standardy organizacyjne oraz standardy postępowania w patomorfologii. Wytyczne dla zakładów/pracowni patomorfologii. 1 ed. Warszawa 2020. 